\title{
SUNCT syndrome
}

INSERM

\section{Source}

INSERM. (1999). Orphanet: an online rare disease and orphan drug data base. SUNCT syndrome. ORPHA:57145

SUNCT syndrome (Short-lasting Unilateral Neuralgiform headache attacks with Conjunctival injection and Tearing) is a primary headache disorder characterized by unilateral trig eminal pain that occurs in association with ipsilateral cranial autonomic symptoms (conjunctival injection and tearing). 